\title{
ESTUDO EXPLORATÓRIO DE VALIDAÇÃO CRUZADA UTILIZANDO METODOLOGIA DEA NAS ESCOLAS NOTA DEZ DE SOBRAL, CARIRÉ, FRECHEIRINHA, MASSAPÊ/CE (ANO BASE 2013)
}

http://dx.doi.org/10.5902/2318133818868

\author{
Karlane Holanda Araújo \\ Universidade Federal do Ceará, Brasil. \\ Raimundo Hélio Leite \\ Universidade Federal do Ceará, Brasil.
}

\begin{abstract}
Resumo
O governo do Estado do Ceará, por meio da Secretaria da Educação - Seduc -, vem implantando validações educacionais orientadas pelo modelo accountability desde o ano de 2003. Uma dessas ações, no sentido de orquestrar a melhoria da qualidade educacional, é denominada Prêmio escola nota dez, uma medida de incentivo e reconhecimento aos bons resultados das escolas frente à meta de alfabetizar todos os alunos do $2^{\circ}$ ano. Considerando que os indicadores educacionais para premiação das escolas são extraídos do Sistema Permanente de Avaliação da Educação Básica do Ceará - Spaece/Alfa -, realizou-se um estudo exploratório, de validação cruzada, com o objetivo de verificar a consistência e reprodutividade dos resultados das escolas de excelência propagados pelo Prêmio escola nota dez. Para isso, aplicou-se o modelo Análise Envoltória de Dados - DEA - em 91 escolas aferidas pelo Spaece, nos municípios de Sobral, Frecheirinha, Cariré e Massapê, no período de 2013, a fim de comparar com os índices de eficiência nas DMUs. O estudo revelou que há concordância entre os modelos. Os resultados demonstraram que as 16 escolas premiadas - DMUs - obtiveram índice de eficiência aceitável entre 0,90 e 1,0, no DEA, constatando que as escolas nota dez também foram consideradas escolas de excelência pelo modelo DEA. Essa confluência entre os modelos indica que os resultados do Spaece/Alfa possibilitam subsídios confiáveis para avaliar a eficiência das escolas. Porém, a validação cruzada mostrou ainda que existem 33 escolas, dentro da curva de eficiência, mas que não receberam o Prêmio escola nota dez. Neste aspecto, a análise carece de ponderação, pois para que a unidade escolar seja contemplada com o Prêmio escola nota dez além de atingir a proficiência desejada, há também a exigência de que o município onde ela se localiza, obtenha pelo menos $70 \%$ dos alunos, do 2 ano, com o nível Desejável na escala Spaece/Alfa. Além disso, a escola precisa está entre as 150 do ranking com as melhores proficiências estudantis do estado do Ceará. Assim, seria necessário um estudo mais aprofundado para averiguar os fatores dessa discrepância revelada.

Palavras-chave: avaliação, DEA, prêmio escola nota dez.
\end{abstract}




\title{
VALIDATION EXPLORATORY STUDY CROSS IN SCHOOLS USING DEA \\ METHODOLOGY NOTE TEN SOBRAL, CARIRÉ, FRECHEIRINHA, MASSAPÊ/CE (BASE YEAR 2013)
}

\begin{abstract}
The Government of the State of Ceará, through the Department of Education - Seduc -, has been implementing educational validations guided by accountability model since 2003 . One of these actions in order to orchestrate the improvement of educational quality, is called School award note ten, a measure of encouragement and recognition to the good results of schools across the literacy goal of all students of the 2nd year. Whereas the educational indicators for awards schools are extracted from the Permanent System of Evaluation of Basic Education of Ceará - Spaece/Alfa -, there was an exploratory study, cross-validation, in order to check the consistency and reproducibility of the results of excellent schools propagated by School award note ten. Or this, we applied the data envelopment analysis model - DEA - in 91 measured by Spaece schools in the municipalities of Sobral, Frecheirinha, Cariré Massapê and, from 2013, in order to compare with the contents efficiency in DMUs. The study revealed that there is agreement between models. The results showed that the 16 winning schools - DMUs - obtained acceptable efficiency ratio between 0.90 and 1.0, the DEA, noting that the schools note ten were also considered schools of excellence by the DEA model. This confluence of the models indicates that the results of Spaece/Alfa enable reliable subsidies to evaluate the efficiency of schools. However, the cross-validation also showed that there are 33 schools, inside the efficiency curve, but which have not received the Award school note dec. In this respect, the analysis lacks balance, because for that school unit to be awarded the Note Award Ten in addition to achieving the desired proficiency, there is also the requirement that the municipality where it is located, obtain at least $70 \%$ of students, $2^{\text {nd }}$ year, with the level Desirable in Spaece/Alfa scale. In addition, the school needs is among the 150 ranking with the best student proficiencies in Ceará. Thus, further study to determine the factors that revealed discrepancy would be required.

Key-words: evaluation, DEA, award school note ten.
\end{abstract}




\section{Introdução}

importância da educação para o desenvolvimento econômico e social é 4 consenso na literatura especializada, sendo necessário priorizar os investimentos públicos em políticas voltadas para a sua melhoria, bem como prever uma forma objetiva de mensurar seu progresso relativo e absoluto, que ateste a eficácia ou o fracasso das ações tomadas.

Nos Estados Unidos, a partir da década de 1980, foram implantadas as políticas de responsabilização ou accountability, que consistem em atribuir a equipe escolar coresponsabilidade em face às medidas e metas de desempenho educacional alcançadas.

No Brasil, esse modelo de gestão por prestação e rendição de contas, foi introduzido no início dos anos 1990, justamente quando se instalava no país o regime democrático de administração pública (Pinho; Sacramento, 2009). O modelo inglês accountability imperou na área educacional brasileira, mediante a centralização do currículo, criação de sistemas de avaliação e descentralização das ações governamentais (Earl, 1999; Escudero, 2003).

Nesse intento, a avaliação educacional em larga escala tornou-se impositiva para levantar informações, monitorar, acompanhar e redirecionar as tomadas de decisões que focalizam a eficiência e a eficácia da educação nacional. Em acordo com o discurso das descentralizações das ações governamentais e do regime de colaboração previstos no Plano Nacional de Educação, decênio 2001-2010, os Estados e municípios também organizaram seus sistemas de avaliação das aprendizagens como mecanismo para subsidiar o processo de formulação e monitoramento das políticas públicas.

Com a introdução da prática de gestão direcionada aos resultados, o governo faz uso de mecanismos de incentivos criados e firmados, por leis estaduais ${ }^{1}$, por meio do rateio da cota parte do Imposto sobre Circulação de Mercadorias e Prestação de Serviços - ICMS - e premiação de municípios com melhor desempenho de aprendizado na sua rede de educação básica, como destacam Petterini e Irffi (2013).

Uma dessas ações de indução à melhoria da qualidade educacional é denominada Prêmio escola nota dez. De acordo com Coelho (2013), o prêmio é uma medida de incentivo e reconhecimento aos bons resultados das escolas com a meta de alfabetizar todos os alunos do $2^{\circ}$ ano.

O programa Escola nota dez faz uso do Sistema Permanente de Avaliação da Educação Básica - Spaece $-^{2}$ para aferir, comparar e premiar escolas. O prêmio concentra-se em identificar os insumos educacionais de maior peso no aprendizado dos alunos e que possam ser reproduzidos em larga escala.

Considerando que os dados e indicadores educacionais para premiação das escolas são gerados pelo Spaece que, em tese, permitem produzir diagnósticos sobre a situação, desempenho e qualidade da educação básica no Ceará, surge a questão norteadora do presente estudo: os resultados do Spaece possibilitam subsídios confiáveis para avaliar a eficiência das escolas e premiá-las?

\footnotetext{
1 Lei n. 14.023, de 17 de dezembro de 2007, que define critérios para distribuição da parcela de receita do produto e arrecadação de impostos no Estado do Ceará; Lei 15.052, de dezembro de 2011, que disciplina o Prêmio escola nota dez.

2 O governo do Estado do Ceará, por meio da Secretaria da Educação - Seduc -, implantou, desde 1992, o Sistema Permanente de Avaliação da Educação Básica do Ceará - Spaece. Na vertente avaliação de desempenho acadêmico, o Spaece caracteriza-se como avaliação externa em larga escala que avalia as competências e habilidades dos alunos do ensino fundamental e do ensino médio, em Língua Portuguesa e Matemática.
} 
O objetivo desta pesquisa foi verificar a consistência e reprodutividade dos resultados das escolas de excelência propagados pelo Prêmio escola nota dez. Para isso, aplicou-se o modelo DEA em 91 escolas da região do Sertão Norte do Ceará, dos municípios de Sobral, Frecheirinha, Massapê e Carriré, ano de referência 2013, a fim de comparar com os índices de eficiência do DMUs utilizado pelo Spaece-Alfa.

Este estudo, em que pese ser exploratório e inicial, é um esforço no sentido de buscar mostrar a confiabilidade dos resultados do programa Escola nota dez.

\section{Prêmio escola nota dez: instrumento de gestão da política de alfabetização no Ceará}

A Assembléia Legislativa do Estado do Ceará, preocupada com a situação de analfabetismo das crianças da rede pública de ensino, instituiu em 2004 o Comitê Cearense para a Eliminação do Analfabetismo Escolar. Foi feita uma pesquisa detalhada sobre a situação do analfabetismo no Ceará. O diagnóstico revelou que $40 \%$ dos alunos, da amostra representativa de cerca de 8.000 , foram considerados alfabetizados (Marques; Aguiar; Campos, 2009; Marques et al., 2006).

Os resultados foram apresentados e discutidos com gestores escolares e professores. Gerando uma mobilização das prefeituras de 60 municípios que, sob a coordenação da Associação dos Prefeitos do Estado do Ceará - Asprece - e da Undime/CE, com apoio do Unicef instituíram, em 2006, o Programa Alfabetização na Idade Certa - Paic.

Atualmente, o referido programa contempla todos os 184 municípios cearenses e está voltado para melhoria dos indicadores de alfabetização na idade certa. Os índices são constatados pelo Spaece-Alfa e tem por finalidade identificar o nível de leitura em que se encontram os alunos da escola pública ao término do $2^{\circ}$ ano do ensino fundamental, no final do ano letivo.

Dentro desse contexto, o Spaece-Alfa consiste numa avaliação anual, externa e censitária que possibilita a construção de indicadores de qualidade sobre a habilidade em leitura de cada aluno. Esse indicador estabelece comparações com os resultados das avaliações realizadas pelos municípios e pelas avaliações externas nacionais (Ceará, 2009b).

Após a aplicação em larga escala, os resultados dos testes das crianças são apresentados aos municípios utilizando a seguinte escala de proficiência: i) abaixo de 75 pontos: crianças não alfabetizadas; ii) de 75 a 100 pontos: alfabetização incompleta; iii) de 100 a 125 pontos: intermediário; iv) de 125 a 150 pontos: suficiente; v) mais de 150: nível desejado. Essa escala permite a verificação da avaliação individual de cada criança, escola, município. Apesar dos resultados poderem ser dados individualmente, seu foco é todo o sistema educacional avaliado: a turma, a escola, a regional, o Estado (Ceará, 2008, 2009, 2010).

O Paic conta com uma ação estratégica intitulada Prêmio escola nota dez, que mobiliza os municípios, as escolas e os professores alfabetizadores a melhorarem a proficiência estudantil em português e matemática. O prêmio é disciplinado pela a lei $\mathrm{n}$. 15.052, de 6 de dezembro de 2011, "com o objetivo de fortalecer, valorizar e ampliar o trabalho que vem sendo empreendido pelas escolas em relação aos resultados de alfabetização"(Lets, 2012, p. 11). 
O desempenho administrativo e pedagógico das escolas premiadas pode ser traduzido, quantitativamente, por meio do Índice de Desenvolvimento EscolarAlfabetização - IDE/Alfa. O Índice de Desenvolvimento Escolar - IDE - foi criado a fim de expressar de maneira clara o desempenho das escolas nas avaliações do Spaece, em uma escala que varia entre 0 e 10. Esse índice possui duas versões: o IDE-Alfa, que representa o desempenho da escola no processo de alfabetização e tem seu cálculo efetuado com base nos resultados do Spaece-Alfa e, ainda, o IDE 5 que mede a proficiência média em Língua Portuguesa e Matemática no $5^{\circ}$ ano do ensino fundamental, calculado com base na avaliação do Spaece. O IDE é composto por três elementos: a proficiência da escola, convertida para uma escala de 0 a 10, a taxa de participação na avaliação e o fator de ajuste para a universalização do aprendizado, que tem por finalidade estimular as escolas a incluírem um maior percentual de alunos nos níveis adequados (Carneiro; Irffi, 2014).

O prêmio estipula os critérios para aferir a eficiência da aprendizagem dos alunos, premia às 150 escolas com os melhores resultados: aquelas obtenham IDE/Alfa no intervalo entre 8,5 e 10,0, IDE/ 5 entre 7,5 e 10,0. Além disso, oferece aporte financeiro às 150 escolas com os mais baixos desempenhos. Como condicionantes, a escola, para ser agraciada com o prêmio, tem que ter no mínimo 20 alunos matriculados na série em questão, bem como ter pelo menos $90 \%$ destes avaliados. Há também a exigência de que, pelo menos, $70 \%$ dos alunos do $2^{\circ}$ ou $5^{\circ}$ ano que alcancem o nível desejável na escala Spaece. Por fim, estabelece que

o valor da premiação por escola é calculado considerando a per capita por aluno de $\mathrm{R} \$ 2.000,00$, (dois mil reais) correspondente à multiplicação do número de alunos do segundo e do quinto anos do ensino fundamental avaliados pelo SPAECE. As escolas com menores IDE-Alfa e IDE 5 receberão contribuição financeira equivalente à multiplicação do número de alunos do $2^{\circ}$ e do $5^{\circ}$ anos do ensino fundamental pelo valor per capita de $R \$ 1.000,00$ (hum mil reais), para implementação do plano de melhoria dos resultados de alfabetização e $5^{\circ}$ ano para as escolas que obtiveram os menores resultados no IDE-Alfa e IDE $5 .^{3}$

Tendo em vista que o prêmio funciona como um instrumento de gestão educacional para a melhoria da educação básica, com foco especial na etapa de alfabetização, faz-se necessário conferir e confrontar seu modelo de classificação das escolas eficientes com outros modelos a fim de dirimi dúvidas a cerca de sua confiabilidade e reaplicabilidade.

\section{Análise da eficiência escolar}

A produção de um bem ou serviço reúne certos tipos de insumos e os combina de tal forma que resulte em um ou mais produtos. Como e quanto produzir envolve combinações que podem gerar o máximo de produto ou serviço, o que se convencionou de eficiência.

A eficiência de uma instituição está associada à sua competência administrativa em gerenciar, propositivamente, os recursos financeiros, materiais e humanos em resultados, potencializando a relação custo-benefício.

${ }^{3}$ Disponível em: <http://www.paic.seduc.ce.gov.br/index.php/o-paic/premio-escola-nota-10>. Acesso em 24 maio 2015. 
O indicador de eficiência aponta a habilidade da administração organizacional de transformar em resultados os recursos disponíveis, otimizando a relação custo-benefício. Valarelli (1999, p. 4) acentua que "a eficiência diz respeito à boa utilização dos recursos financeiros, materiais e humanos em relação às atividades e resultados atingidos".

O conceito de eficiência pode ser encontrado de diversas formas. Conforme Afonso (2007), eficiência pode ser: eficiência técnica, alocativa e econômica.

A eficiência técnica está relacionada à conversão de insumos físicos em produtos materiais, com melhor prática - teórica ou observada - em uma determinada amostra de unidades de produção, podendo ser países, organizações ou setores de uma mesma organização. Nesse sentido, dada a tecnologia corrente, não deverá haver perda de insumos, qualquer que seja para produzir a quantidade de produtos. A melhor prática verificada em comparação com todos os outros na amostra é dita ser totalmente eficiente tecnicamente (100\% de eficiência). A eficiência técnica, expressa em percentagem das melhores práticas, é baseada em relações técnicas, mas não nos preços ou custos (Abel, 2000).

A eficiência alocativa verifica se os insumos, dado um nível de produto e o preço dos insumos, são escolhidos para minimizar os custos de produção, relaciona a capacidade de reduzir os custos de produção com a capacidade da decisão no uso dos vários inputs em proporções ótimas. Para isso, a organização analisada já deve ser tecnicamente eficiente. A eficiência alocativa também pode ser expressa em porcentagem, em que o escore de $100 \%$ indica que a instituição usa seus insumos numa proporção em que custos são minimizados (Sousa, 2007).

Farrel (1957) propôs que a eficiência de uma instituição consiste de dois componentes: eficiência técnica, que reflete a habilidade de uma organização para obter output máximo para um dado conjunto de inputs, e eficiência alocativa, que significa a habilidade da organização em usar proporções ótimas, mediante seus respectivos preços e a produção tecnológica. Tais medidas, quando combinadas, fornecem a medida de total eficiência econômica.

Mas como saber se uma instituição é eficiente? Uma maneira é comparando-a com outras. A eficiência é dada comparando o produto obtido ao máximo observado, dados os insumos. Se ela for eficiente, ela utiliza seus insumos de maneira a obter o máximo possível de produtos e/ou serviços.

Conforme Farrell (1957) o sucesso em produzir o melhor produto dados os insumos define uma organização eficiente. Ineficiência técnica é o fracasso para alcançar a fronteira de eficiência (Charnes; Cooper, 1990).

Charnes, Cooper, Rhodes (1978) estenderam a idéia de Farrell e propuseram um modelo que generalizava a razão produto/insumo para o caso de organizações que utilizam múltiplos insumos e produziam múltiplos produtos se para os quais não era possível atribuir preços. Este modelo é denominado de Análise Envoltória de Dados DEA - Data Envelopment Analysis -, uma metodologia com capacidade de comparar a eficiência de múltiplas unidades de serviço que fornecem serviços similares mediante a consideração explícita do uso de seus múltiplos recursos, na produção de múltiplos serviços (Charnes et. al, 1994). 


\section{O modelo Data Envelopment Analysis - DEA}

O DEA é um método de fronteira, não paramétrico, que tem como objetivo avaliar a eficiência relativa, comparando o desempenho de uma unidade produtiva a um parceiro de excelência - benchmark -, quando há múltiplos insumos e múltiplos produtos a serem considerados na análise do sistema produtivo. Apresenta como resultado uma fronteira de eficiência que representa a melhor prática produtiva e calcula os índices de eficiência em relação a essa fronteira. Para utilizá-lo, não é preciso especificar qualquer forma funcional para as funções de produção e custo (Silva, 2006).

De acordo com Charnes, Cooper e Rhodes (1978 apud Meirelles, 2012, p. 14) a metodologia DEA

contabiliza explicitamente múltiplas entradas e saídas de forma abrangente e confiável tendo como resultado o conjunto de índices de eficiência das unidades avaliadas. Assim, a metodologia DEA pode ser utilizada para comparar um grupo de unidades de serviços a fim de identificar as unidades relativamente menos eficientes, medindo a magnitude das ineficiências, e, pela comparação das unidades não eficientes com as eficientes, diagnosticar possíveis causas para a ineficiência destas unidades.

Este tipo de análise é construída a partir de uma medida que contabiliza a soma ponderada dos produtos pela soma ponderada dos insumos, que fornece a eficiência de cada unidade.

No âmbito educacional a eficiência dos serviços prestados pode ser mensurada pelas avaliações externas, que servem como instrumentos de dados para aferir a qualidade técnica das instituições escolares. A qualidade da educação, no caso em estudo, está relacionada aos níveis de proficiências em português pelo Spaece/Alfa. Embora o nível de educação avaliado seja nos anos iniciais, em crianças, os princípios universais do que se entende por avaliação de qualidade se aplicam a todo o sistema.

É nessa direção que a proposta do Prêmio escola nota dez caminha, comparando a eficiência técnica, que reflete a habilidade de uma organização para obter output máximo para um dado conjunto de inputs e eficiência alocativa. Esse instrumento de gestão da avaliação tem implicação política administrativa, na medida em que envolve prestação de contas dos serviços educacionais, publicização dos resultados, alocação de recursos financeiros e bonificação dos professores. Além disso, ao longo do tempo, se a instituição de ensino não atingir níveis de eficiência aceitáveis pelos órgãos competentes, pode vir a sofrer medidas corretivas como o próprio fechamento da escola.

Portanto, há necessidade dos gestores educacionais adotarem práticas avaliativas confiáveis, que possam ser submetidas a comparações de eficiência entre as unidades do sistema. Há um modelo linear que realiza este tipo de tarefa.

Com efeito,

a Análise Envoltória de Dados - DEA - é uma técnica matemática de programação linear desenvolvida por Charnes, Cooper e Rhodes (1978) e estendida por Banker, Charnes e Cooper (1984), que converte medidas de múltiplos insumos e produtos em uma única medida de eficiência. Ela propicia que se analise a eficiência comparativa de organizações complexas, comparação esta obtida pela revelação do desempenho de outras unidades, de modo que a referência não é obtida apenas teórica ou 
conceitualmente, mas através da observação das melhores práticas. As organizações que estiverem sob análise DEA são denominadas Decision Making Units (DMU) e deverão ter em comum a utilização dos mesmos recursos e produzir os mesmos produtos. (Forchezatto, 2010, p. 4).

A proposta desse estudo é aplicar a metodologia DEA nas escolas do Sertão Norte cearense (Sobral, Frecheirinha, Massapê e Carriré), avaliadas pelo Spaece/Alfa, no ano de 2013, a fim de realizar uma validação cruzada para constatar os índices de eficiência.

\section{Análise dos resultados}

Critérios usados pela Seduc

Os critérios empregados pela Seduc para classificar o desempenho das escolas envolvem taxa da participação da avaliação, o fator de ajuste do aprendizado para língua portuguesa do $2^{\circ}$ ano e o cálculo da proficiência ajustada dos municípios.

Variáveis de input e output

Para a execução do modelo foram utilizadas as seguintes variáveis:

Variáveis de output:

- profMedia: referente à proficiência em língua portuguesa da DMU.

- ideantigo: índice de desenvolvimento escolar referente à 2012.

Variáveis de input:

- totPart: total de alunos que fizeram a prova.

- ideatual: índice de desenvolvimento escolar referente à 2013.

\section{Resultados com a aplicação do DEA}

De um total de 8.601 escolas avaliadas pelo Sistema Permanente de Avaliação da Educação Básica do Ceará - Spaece, em 2013, foram analisadas 91 escolas pertencentes aos municípios de Sobral, Frecheirinha, Massapê e Cariré, estas consideradas DMU's e executadas utilizando a metodologia DEA.

As 91 escolas avaliadas estão distribuídas: 35 são do município de Sobral, 10 de Frecheirinha, 26 de Massapê e 20 de Cariré.

Das 91 escolas, apenas 16 foram contempladas pelo Prêmio escola nota dez (2013).

Quadro 1 -

Escolas contempladas pelo Prêmio escola nota dez de Sobral, Frecheirinha, Massapê e Cariré (2013) e suas respectivas classificações DMU's.

\begin{tabular}{|c|c|c|c|}
\hline Município & Código da escola & Escola & $\begin{array}{l}\text { Classificação } \\
\text { Dmus }\end{array}$ \\
\hline Cariré & 23017791 & $\begin{array}{l}\text { Adauta Mocinha Barros Rocha } \\
\text { Eeief }\end{array}$ & 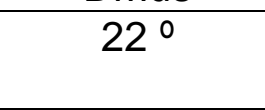 \\
\hline Cariré & 23017937 & Evangelina Feijao Eeief & $23 \stackrel{\circ}{-1}$ \\
\hline Freicheirinha & 23015691 & Abraao Cacula de Almeida Esc & 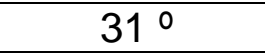 \\
\hline Freicheirinha & 23015845 & Fco Ferreira Pontes Esc & $32 \stackrel{\circ}{=}$ \\
\hline Freicheirinha & 23016035 & Nair Cunha Aguiar Esc & 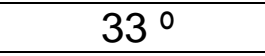 \\
\hline Freicheirinha & 23319615 & Carlos Machado Portela Escola & $34 \stackrel{\circ}{2}$ \\
\hline
\end{tabular}




\begin{tabular}{|c|c|l|c|}
\hline Massapê & 23020709 & Francisca Diogo Gomes Eef & $65^{\circ}$ \\
\hline Massapê & 23171901 & Maria Haury Pontes Eef & $66^{\circ}$ \\
\hline Massapê & 23021314 & $\begin{array}{l}\text { Centro Comunitario São Joao } \\
\text { Batista Eef }\end{array}$ & $67^{\circ}$ \\
\hline Massapê & 23020520 & Aureliano Lopes Eef & $126^{\circ}$ \\
\hline Sobral & 23024780 & Elpidio Ribeiro Da Silva Eief & $127^{\circ}$ \\
\hline Sobral & 23026014 & Leonilia Gomes Parente Eief & $128^{\circ}$ \\
\hline Sobral & 23024569 & Antonio Mendes Carneiro Ei Ef & \multicolumn{1}{c|}{} \\
\hline Sobral & 23186011 & $\begin{array}{l}\text { Raimundo Pimentel Gomes Caic } \\
\text { Eief }\end{array}$ & $130^{\circ}$ \\
\hline Sobral & 23247762 & José da Matta E Silva Eief & $131^{\circ}$ \\
\hline Sobral & 23025115 & Ef. José Erminío de Moraes & \\
\hline
\end{tabular}

Fonte: elaboração própria.

Ao aplicar os dados disponibilizados pela Seduc no modelo DEA, foi obtido como resultado: 42 escolas consideradas eficientes, com o índice de eficiência igual a 1,0. Também existem 43 com índice de eficiência aceitável igual ou superior a 0,90. As 6 escolas restantes, mediante análise do modelo DEA, são tidas como ineficientes.

Verifica-se que, do conjunto das seis escolas ineficientes, quatro estão localizadas em Massapé (23240946; 23171928; 23020750; 23171960), uma tem sede em Cariré (23018151), uma em Frecheirinha (23016027). Nesse aspecto, não consta escola ineficiente no município de Sobral.

A classificação das escolas de acordo com a metodologia DEA é apresentada no quadro 2.

Quadro 2 -

Ranking das escolas Sobral, Frecheirinha, Massapê e Cariré utilizando metodologia DEA.

\begin{tabular}{|c|c|c|c|c|c|c|c|c|}
\hline Rank & DMU & Score & Rank & DMU & Score & Rank & DMU & Score \\
\hline 1 & 23016051 & $100,00 \%$ & 31 & 23020717 & $100,00 \%$ & 61 & 23186097 & $98,30 \%$ \\
\hline 2 & 23017791 & $100,00 \%$ & 32 & 23026235 & $100,00 \%$ & 62 & 23021110 & $98,08 \%$ \\
\hline 3 & 23017813 & $100,00 \%$ & 33 & 23020822 & $100,00 \%$ & 63 & 23238119 & $98,05 \%$ \\
\hline 4 & 23017821 & $100,00 \%$ & 34 & 23026162 & $100,00 \%$ & 64 & 23025433 & $98,03 \%$ \\
\hline 5 & 23017830 & $100,00 \%$ & 35 & 23026014 & $100,00 \%$ & 65 & 23026375 & $97,92 \%$ \\
\hline 6 & 23017899 & $100,00 \%$ & 36 & 23025913 & $100,00 \%$ & 66 & 23220015 & $97,77 \%$ \\
\hline 7 & 23016000 & $100,00 \%$ & 37 & 23025859 & $100,00 \%$ & 67 & 23025719 & $97,62 \%$ \\
\hline 8 & 23017937 & $100,00 \%$ & 38 & 23025328 & $100,00 \%$ & 68 & 23025379 & $97,46 \%$ \\
\hline 9 & 23017988 & $100,00 \%$ & 39 & 23021314 & $100,00 \%$ & 69 & 23219289 & $97,34 \%$ \\
\hline 10 & 23018011 & $100,00 \%$ & 40 & 23024780 & $100,00 \%$ & 70 & 23021020 & $96,88 \%$ \\
\hline 11 & 23018020 & $100,00 \%$ & 41 & 23196203 & $100,00 \%$ & 71 & 23021357 & $96,77 \%$ \\
\hline 12 & 23018054 & $100,00 \%$ & 42 & 23171901 & $100,00 \%$ & 72 & 23025794 & $96,62 \%$ \\
\hline 13 & 23018062 & $100,00 \%$ & 43 & 23247762 & $99,69 \%$ & 73 & 23017341 & $96,43 \%$ \\
\hline 14 & 23018100 & $100,00 \%$ & 44 & 23220120 & $99,57 \%$ & 74 & 23017929 & $95,83 \%$ \\
\hline 15 & 23018119 & $100,00 \%$ & 45 & 23024569 & $99,56 \%$ & 75 & 23020601 & $95,83 \%$ \\
\hline 16 & 23018135 & $100,00 \%$ & 46 & 23186011 & $99,17 \%$ & 76 & 23026367 & $95,76 \%$ \\
\hline 17 & 23015985 & $100,00 \%$ & 47 & 23195649 & $99,14 \%$ & 77 & 23271558 & $94,64 \%$ \\
\hline
\end{tabular}




\begin{tabular}{|c|c|c|c|c|c|c|c|c|}
\hline 18 & 23018240 & $100,00 \%$ & 48 & 23025301 & $99,04 \%$ & 78 & 23015993 & $94,26 \%$ \\
\hline 19 & 23018259 & $100,00 \%$ & 49 & 23026138 & $99,00 \%$ & 79 & 23021004 & $94,23 \%$ \\
\hline 20 & 23268468 & $100,00 \%$ & 50 & 23026081 & $99,00 \%$ & 80 & 23194740 & $93,75 \%$ \\
\hline 21 & 23331216 & $100,00 \%$ & 51 & 23020520 & $98,91 \%$ & 81 & 23020695 & $93,57 \%$ \\
\hline 22 & 23015845 & $100,00 \%$ & 52 & 23026154 & $98,91 \%$ & 82 & 23229276 & $92,55 \%$ \\
\hline 23 & 23020423 & $100,00 \%$ & 53 & 23016035 & $98,86 \%$ & 83 & 23021071 & $92,50 \%$ \\
\hline 24 & 23020474 & $100,00 \%$ & 54 & 23220058 & $98,81 \%$ & 84 & 23021454 & $92,39 \%$ \\
\hline 25 & 23020512 & $100,00 \%$ & 55 & 23229284 & $98,67 \%$ & 85 & 23015977 & $91,67 \%$ \\
\hline 26 & 23015691 & $100,00 \%$ & 56 & 23319615 & $98,65 \%$ & 86 & 23018151 & $89,29 \%$ \\
\hline 27 & 23020555 & $100,00 \%$ & 57 & 23025425 & $98,46 \%$ & 87 & 23240946 & $87,50 \%$ \\
\hline 28 & 23026340 & $100,00 \%$ & 58 & 23025743 & $98,44 \%$ & 88 & 23171928 & $82,14 \%$ \\
\hline 29 & 23026308 & $100,00 \%$ & 59 & 23021292 & $98,44 \%$ & 89 & 23020750 & $81,58 \%$ \\
\hline 30 & 23020709 & $100,00 \%$ & 60 & 23025115 & $98,36 \%$ & 90 & 23016027 & $76,92 \%$ \\
\hline
\end{tabular}

Fazendo um comparativo entre as duas metodologias, evidencia-se que as 16 escolas DMUs agraciadas pelo Prêmio Escola Nota, em 2013, ao serem avaliadas utilizando o modelo DEA, se apresentam como escolas eficientes. Sendo que nove escolas DMUs, revelam índice de eficiência no DEA igual a 1,0, e as outras sete escolas, tem índice aceitável igual a 0,90 .

Constata-se que das nove escolas com padrão máximo de eficiência DEA, duas são de Cariré $(23017791 ; 23017937)$, duas de Frecheirinha (23015845; 23015691), duas de Sobral $(23186011 ; 23024569)$ e três de Massapê( 23020709; 23171901; 23021314).

Já das sete escolas com índice aceitável até 0,90, identifica-se uma em Massapê (23020520), duas em Frecheirinha $(23016035,23319615)$ e três em Sobral (23247762, 23186011, 23025115, 23024569).

Observa-se, ainda, a existência de 33 escolas, dentro da curva de eficiência, com índice igual a 1,0 pela metodologia DEA, mas que não receberam o Prêmio escola nota dez. Contudo, tal análise carece de ponderação, pois para a unidade escolar ser contemplada com o Prêmio escola nota dez além de atingir a proficiência desejada, há também a exigência de que o município onde ela se localiza, deve obter pelo menos $70 \%$ dos alunos do $2^{\circ}$ ano com o nível desejável na escala Spaece/Alfa. Além disso, a escola precisa está entre as 150 do ranking com as melhores proficiências estudantis do estado do Ceará. Por isso, seria necessário um maior aprofundamento para averiguar essa discrepância revelada.

Diante dos dados apresentados, conclui-se que das 91escolas DMUs analisadas, 85 escolas (89\%) foram consideradas eficientes, com um índice de eficiência aceitável, entre 1 e 0,9 , e seis escolas (6,59\%) ficaram abaixo da fronteira de eficiência. 
Gráfico 1 -

Resultados da eficiência das escolas calculados pelo DEA.

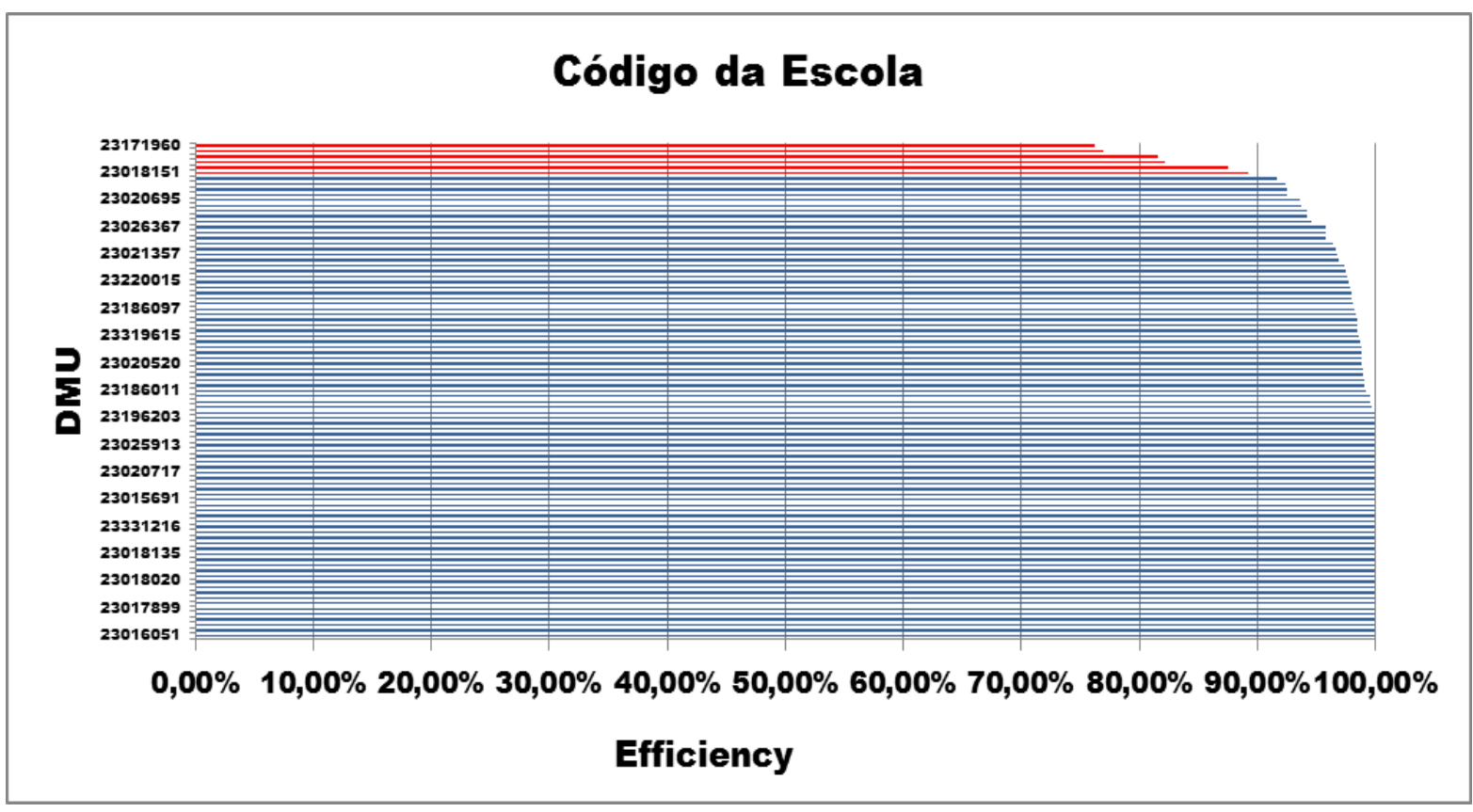

Assim, identifica-se que, na avaliação do DEA, 6,59\% das escolas avaliadas pelo Spaece/Alfa, por não apresentarem índice de eficiência entre 0,90 a 1,0, são consideradas ineficientes, seja referente à taxa de participação no Spaece ou ao percentual de proficiência de desempenho da alfabetização.

\section{Considerações finais}

O estudo de validação cruzada entre o modelo DMUs, adotado pela Seduc, e a aplicação da metodologia DEA, em 91 escolas que participaram do Spaece/Alfa, nas cidades de Sobral, Frecheirinha, Cariré e Massapê, revelou que há concordâncias.

Os resultados demonstram que as 16 premiadas - DMUs - obtiveram índice de eficiência aceitável no DEA, constatando uma convergência entre os modelos. As escolas nota dez foram consideradas escolas de excelência pelo modelo DEA. Essa confluência entre os modelos indica que os resultados do Spaece/Alfa possibilitam subsídios confiáveis para avaliar a eficiência das escolas.

Entretanto, vale destacar que existem 33 escolas com índice de eficiência igual a 1,0, que não receberam a premiação de Escola nota dez, ficando fora do ranking do prêmio. A validação cruzada entre os modelos necessita de um maior aprofundamento a fim de atestar quais as exigências dos quesitos de premiação que as demais escolas não atenderam a contento.

Apesar de o estudo ser de caráter exploratório, os resultados encontrados são suficientes para que se realize análise em maior número de unidades educacionais do Estado, incluindo variáveis independentes sobre os professores, tais como qualificação, tempo dedicado à orientação do aluno, frequência das tarefas escolares, dentre outras. A ampliação desse estudo, em grandes amostras, possibilitará realizar comparações mais consistentes para constatação da confiabilidade e robustez do Prêmio escola nota dez. 


\section{Referências}

ABEL, Lecir. Avaliação cruzada da produtividade dos departamentos acadêmicos da UFSC utilizando DEA (Data Envelopment Analysis). Florianópolis: Universidade Federal de Santa Catarina, 2000.

AFONSO, Antônio. A eficiência do estado. In: BOUERI, Rogério; SABOYA, Maurício. (orgs.). Aspectos do desenvolvimento fiscal. Brasília: Ipea, 2007, p. 111-124.

BANKER, Rajiv; CHARNES, Abraham; COOPER, William. Some models for estimating technical scale inefficiencies in data envelopment analysis. Management Science, v. 30, 1984, p. 1078-1092.

CARNEIRO, Diego; IRFFI, Guilherme. Política de incentivos a escola melhora a proficiência no ensino fundamental? Uma avaliação do prêmio escola nota dez. ENCONTRO ECONOMIA DO CEARÁ EM DEBATE, 10, 2013. Anais ... Fortaleza: Ipec, 2013.

CEARÁ. Avaliação do ensino fundamental: Spaece-2008. Boletim Pedagógico de Alfabetização: Spaece-Alfa 2008. Juiz de Fora: UFJF, 2008.

CEARÁ. Resultados da avaliação da alfabetização Spaece-alfa 2009. Fortaleza: Seduc, 2009a.

CEARÁ. Avaliação do ensino fundamental: Spaece-10. Boletim Pedagógico de Alfabetização: Spaece- Alfa 2010. Juiz de Fora: UFJF, 2010.

CEARÁ. O sistema permanente de avaliação do estado do Ceará: da proposta às intervenções educacionais. Fortaleza: Seduc, 2009b.

CEARÁ. Secretaria da Educação. Prêmio escola nota dez. Disponível em: $<$ http://www.paic.seduc.ce.gov.br/index.php/o-paic/premio-escola-nota-10>. Acesso em maio 2015.

COELHO, Maria Izolda Cela de Arruda. Rede de cooperação entre escolas: uma ação no âmbito do programa alfabetização na idade certa. Juiz de Fora: UFJF, 2013.

CHARNES, Abraham; COOPER, William; RHODES, Edward. Measuring the efficiency of decision-making units. European Journal of Operational Research, 2, 1978, p. 429-444.

CHARNES, Abraham; COOPER, William Wagner. Data envelopment analysis. Operational Research, v. 90, 1990, p. 641-645.

CHARNES, Abraham; COOPER, William; LEWIN, Arie; SEIFORD, Lawrence. Data envelopment analysis: theory, methodology and application. Boston: Kluwer Academic Publishers, 1994.

EARL, Lorna. Assessment and accountability in education: improvement or surveillance? Education Canada OISE/UT, 1999.

ESCUDEIRO, Escorza Tomás. Desde los tests hasta La investigación evaluativa actual: um siglo, el XX, de intenso desarrollo de la evaluación en educación. Relieve, v.9, n. 1, 2003, p. 11-43.

FARREL, Michael. The measurement of productive efficiency. Journal of the Royal Statistical Society, Series A, 120, part 3, 1957, p. 253-281.

FORCHEZATTO, Adelar. Análise da eficiência relativa dos tribunais da justiça estadual brasileira utilizando o método DEA. REUNIÓN DE ESTUDIOS REGIONALES, 36, 2010. Anais... Badajoz: AECR, 2010. 
INSTITUTO DE ESTUDOS DO TRABALHO E SOCIEDADE. Análise do uso dos resultados do Spaece/Alfa e das avaliações do prêmio Escola Nota Dez. Rio de Janeiro: IETS, 2012.

MARQUES, Claúdio de Albuquerque et al. Qual o nível de alfabetização das crianças do Ceará. In: Aguiar, Rui Rodrigues; Ivo Ferreira Gomes; Campos, Márcia Oliveira Cavalcante (org.). Relatório final do comitê cearense para a eliminação do analfabetismo escolar: educação de qualidade começando pelo começo. Fortaleza: Assembléia Legislativa do Ceará, 2006.

MARQUES, Cláudio de Albuquerque; AGUIAR, Rui Rodrigues; CAMPOS, Márcia Oliveira Cavalcante. Programa alfabetização na idade certa: concepções, primeiros resultados e perspectivas. Est. Aval. Educ., São Paulo, v. 20, n. 43, 2009, p. 275-291.

MEIRELES, Alandson Mendonça Ribeiro. Uma proposta de SAD para avaliação da eficiência do Poder Judiciário do Estado do Ceará utilizando AED. Fortaleza: UFC, 2012. 112f. Dissertação (mestrado em Computação Aplicada). Universidade Estadual do Ceará; Instituto Federal de Educação, Ciência e Tecnologia do Ceará.

PETTERINI, Francis Carlo; IRFFI, Guilherme Diniz. Evaluating the impact of a change in the ICMS tax law in the state of Ceará in municipal education and health indicators. Economia. Av., v. 14, n. 3-4, 2013, p. 171-184.

PINHO, José Antonio Gomes de; SACRAMENTO, Ana Rita Silva. Accountability: já podemos traduzi-la para o português? Rev. Adm. Pública [online], v. 43, n. 6, 2009, p. 1343-1368.

SANDER, Benno. Administração da educação no Brasil: genealogia do conhecimento. Brasília: Liber Livro, 2007.

SOUZA, Luciano; Aplicação de data envelopmente analysis - DEA - para obtenção de mapas de exclusão e inclusão social. Recife: Universidade Federal Rural de Pernambuco, 2007.

VILELA, Dirley Lemos; NAGANO, Marcelo Seido; MERLO, Edgard Monforte. Aplicação da análise envoltória de dados em cooperativas de crédito rural. RAC, 2007, p. 99-120.

Karlane Holanda Araújo é estudante do curso de mestrado em Educação Brasileira pela Universidade Federal do Ceará.

Endereço: Rua Nove, 92/1032, bl. C - 61635-270 - Caucaia - CE - Brasil.

E-mail: karlaneufc@gmail.com.

Raimundo Hélio Leite é professor no Programa de Pós-Graduação em Educação. Foi reitor da Universidade Federal do Ceará no interstício de 1987 a 1991. Endereço: Rua Eretides Martins, 1667 - 60320-350 - Fortaleza - CE - Brasil. E-mail: rhleite@terra.com.br.

Recebido em 20 de julho de 2015.

Aceito em 28 de setembro de 2015. 